Original article

\title{
Child maltreatment is mediating long-term consequences of household dysfunction in a population representative sample
}

\author{
Vera Clemens ${ }^{\mathrm{a}, \mathrm{b}, *}$, Oliver Berthold ${ }^{\mathrm{a}}$, Andreas Witt $^{\mathrm{a}}$, Cedric Sachser $^{\mathrm{a}}$, Elmar Brähler ${ }^{\mathrm{c}}$, \\ Paul L. Plener ${ }^{\mathrm{a}, \mathrm{d}}$, Bernhard Strauß ${ }^{\mathrm{e}}$, Jörg M. Fegert ${ }^{\mathrm{a}}$ \\ a Department for Child and Adolescent Psychiatry/Psychotherapy, University of Ulm, Steinhövelstr. 5, 89073 Ulm, Germany \\ ${ }^{\mathrm{b}}$ Department of Psychiatry and Psychotherapy, Section Clinical Neurobiology, Campus Benjamin Franklin, Charité - University Medicine Berlin, \\ Hindenburgdamm 30,12203, Berlin, Germany \\ ${ }^{\mathrm{c}}$ Department for Psychosomatic Medicine and Psychotherapy, University Medical Center of Johannes Gutenberg University of Mainz, Untere Zahlbacher Str. 8, \\ 55131, Mainz, Germany \\ d Department for Child and Adolescent Psychiatry, Medical University of Vienna, Währingergürtel 18-20, 1090, Vienna, Austria \\ e Institute of Psychosocial Medicine and Psychotherapy, Jena University Hospital, Stoystraße 3, 07740, Jena, Germany
}

\section{A R T I C L E I N F O}

\section{Article history:}

Received 15 October 2018

Received in revised form 28 January 2019

Accepted 29 January 2019

Available online 10 February 2019

\section{Keywords:}

Adverse childhood experiences (ACE)

Child maltreatment

Intimate partner violence (IPV)

Mentally ill parents

Parental substance abuse

Parental separation

\begin{abstract}
A B S T R A C T
Background: Adverse childhood experiences (ACE) exhibit long-lasting consequences on later life and are considered as a major public health problem. ACEs can be divided into household dysfunctions, which affect the child indirectly, and direct maltreatment. As a high correlation between ACEs in general is known, we assessed the risk for child maltreatment associated with the occurrence of household dysfunctions. To provide a better understanding for the mechanisms leading to the deleterious sequelae of ACEs, we furthermore assessed whether the long-term consequences of household dysfunction are mediated by child maltreatment and thereby might be targeted by effective child protection programs.

Methods: A representative sample of the German population above the age of $14(N=2531)$ was assessed in a cross-sectional observational population-based survey.

Results: The data reveal that mental illness of a household member was associated with significantly increased risks for all child maltreatment subtypes (ORs 4.95-5.55), just as household substance abuse (ORs 5.32-6.98), violence against the mother (ORs 4.43-10.26), incarceration of a household member (ORs 6.11-14.93) and parental separation (OR 3.37-4.87). Child maltreatment partially mediated the association of household mental illness, substance abuse and parental separation with later depression, anxiety, life satisfaction and subjective general health status and completely mediated the associations of intimate partner violence (IPV) and incarceration of a household member with anxiety, depression and subjective health status in adulthood.

Conclusions: ACEs linked to household dysfunction are associated with an increased risk for all subtypes of child maltreatment. The assessed widespread consequences of household dysfunction are mediated by child maltreatment. This underlines the role of prevention of child maltreatment in families with household dysfunction and implies child protection as a priority in any interventions.
\end{abstract}

(c) 2019 Elsevier Masson SAS. All rights reserved.

\footnotetext{
* Corresponding author at: Department of Child and Adolescent Psychiatry/ Psychotherapy, University of Ulm, Steinhövelstr. 5, 89073, Ulm, Germany.

E-mail addresses: vera.clemens@uni-ulm.de (V. Clemens),

o.berthold@drk-kliniken-berlin.de (O. Berthold), andreas.witt@uniklinik-ulm.de (A. Witt), cedric.sachser@uniklinik-ulm.de (C. Sachser),

Elmar.Braehler@medizin.uni-leipzig.de (E. Brähler), paul.plener@meduniwien.ac.at (P.L. Plener), bernhard.strauss@med.uni-jena.de (B. Strauß), joerg.fegert@uniklinik-ulm.de (J.M. Fegert).
}

\section{Introduction}

Adverse childhood experiences (ACE) are known to impact life in several ways. Even though there are heterogeneous approaches what to include when ACEs are assessed, they are usually distinguished between ACEs related to household dysfunction and child maltreatment [1]. Household dysfunction are ACEs that affect the child in an indirect way via their environment, and encompass mental illness and substance abuse of any household member, intimate partner violence (IPV), parental separation and incarceration of a household member. Maltreatment, on the other hand, is directed at the child and can be distinguished into 5 


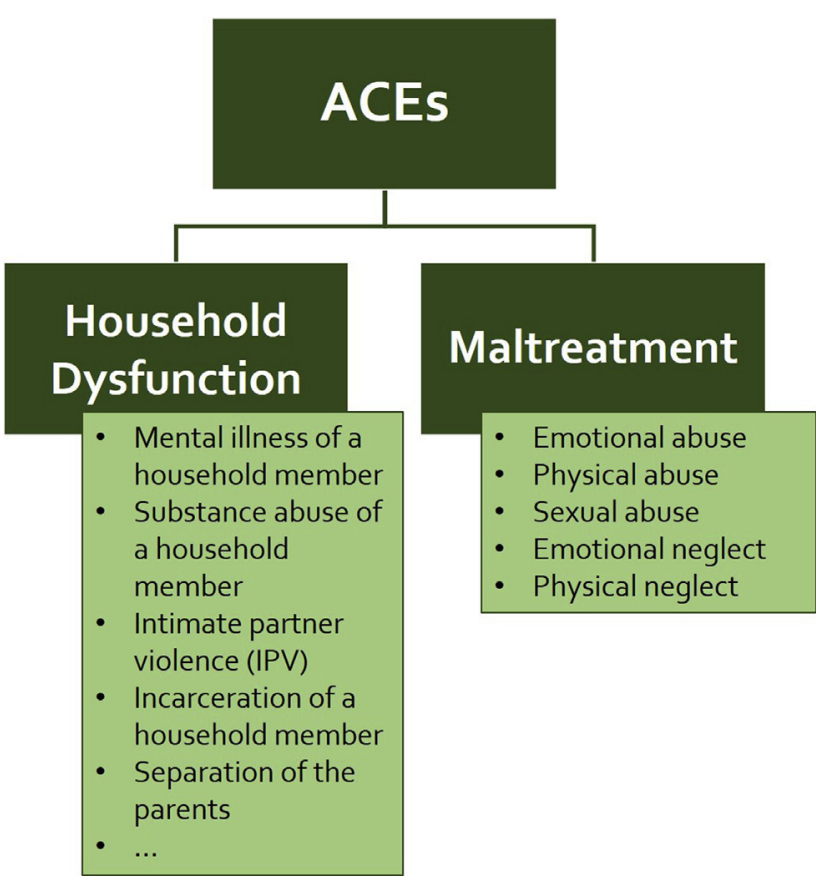

Fig. 1. Overview of adverse childhood experiences. Adverse childhood experiences (ACE) can be divided into household dysfunctions, which affect the child in an indirect way, and child maltreatment.

subtypes: emotional, physical and sexual abuse and emotional and physical neglect (see Fig. 1).

Household dysfunction and child maltreatment often co-occur, are inter-related and have cumulative negative effects $[2,3]$. The number of experienced ACEs is known to have comprehensive effects for mental and somatic health, quality of life [1] and to reduce life expectancy for up to 20 years [4]. Focusing on consequences of specific ACEs, it was shown that ACEs related to both, household dysfunction and child maltreatment, have devastating consequences. Child maltreatment may lead to psychosocial and economic impairment, massive mental and somatic health problems and a significant reduction in quality of life [5]. Next to the individual level, child maltreatment results in enormous economic costs with annual expenses between 11 and 30 billion Euro in Germany alone [6]. Experiences of ACEs related to household dysfunction result in developmental and cognitive impairment [7,8], higher risks for mental disorders [9-12] and social problems [13]. Therefore, household dysfunction and child maltreatment are considered major public health problems.

Several factors are discussed as reasons for the devastating effects of household dysfunctions. Parenting skills and parentchild interactions are known to be impaired in mothers who have experienced IPV [14], as well as in mentally ill [15] and substance abusing parents [16]. Parental separation can go along with reduced contact to one parent and lower secure parent-child attachment [17]. Incarceration usually goes along with separation from a primary caregiver [18]. Moreover, biological and psychosocial factors are hypothesized [19-21]. It was shown for each particular category of household dysfunction to be an important risk factor for child maltreatment by itself $[2,11,22-27]$. This may be one of the main factors for the long-term consequences of household dysfunctions. Unfortunately, to the best of our knowledge, there are no analyses assessing the role of child maltreatment as potential mediator for the observed long-term consequences of household dysfunctions.

This is surprising, as more knowledge about the interplay between household dysfunction and child maltreatment is indispensable for the development of targeted intervention programs in order to reduce the massive impact of ACEs.

Therefore, we investigated the occurrence of child maltreatment in dependence of household mental illness, substance abuse, violence against the mother, incarceration of a household member and parental separation in a population based survey. A population based sample from the age of 14 was chosen to make sure that both short and long term consequences of household dysfunction and maltreatment could be detected. To provide a better understanding for the mechanisms leading to the fatal consequences of ACEs, we furthermore assessed whether the long-term consequences of household dysfunction were mediated by child maltreatment and thereby might be targetable by tailored child protection programs.

\section{Methods}

\subsection{Sample}

Using a random route procedure, a representative sample of the German population was obtained by a demographic consulting company (USUMA, Berlin, Germany). Data collection took place between November 2017 and February 2018. To ensure representativeness a systematic area sampling, based on the municipal classification of the Federal Republic of Germany and covering the entire inhabited area of Germany was used. On the base of this data, around 53,000 areas in Germany were delimited electronically, containing an average of around 700 private households. These areas were first layered regionally according to districts to divide them into a total of around 1500 regional layers. Then 128 so-called networks were drawn in proportion to the distribution of private households. In the second and subsequent third selection stages, private households were selected systematically at random and the respective target persons within these households. Households of every third residence in a randomly chosen street were invited to participate in the study. To select participants in multi-person households a Kish-Selection-Grid was applied. For inclusion, participants had to be at least 14 years of age and have sufficient German language skills. Of 5160 initially contacted households, 2531 persons completed the survey. The main reasons for non-participation were refusal by the selected household to identify the person of target (16.5\%, referring to the initial 5160 households), refusal of the target person to participate (15.8\%) and failure to contact anyone in the residence after four attempts (14.4\%). The resulting sample was representative for the German population above the age of 14 in regard to age and gender.

Individuals who agreed to participate were given information about the study and informed consent was obtained. In the case of minors, participants gave informed assent with informed consent being provided by their caregivers. Participants were told that the study was about psychological health and well-being. Responses were anonymous. In a first step, socio-demographic information was obtained in an interview-format by the research staff face-toface according to the demographic standards of the Federal Statistical Office. Then, the researcher handed out a copy of the questionnaire and a sealable envelope. This questionnaire was answered independently due to the sometimes very personal information provided. The researcher remained nearby in case the participants needed further information or left the household based on the participants wishes. Anyhow, the researcher did not interfere with filling out the questionnaire. The completed questionnaires were linked to the respondent's demographic data, but did not contain name, address, or any other identifying information.

The study was conducted in accordance with the Declaration of Helsinki, and fulfilled the ethical guidelines of the International Code of Marketing and Social Research Practice of the International 
Chamber of Commerce and of the European Society of Opinion and Marketing Research. The study was approved by the Ethics Committee of the Medical Department of the University of Leipzig.

\subsection{Measures}

The prevalence of ACEs was assessed using the German Version of the Adverse Childhood Experiences Questionnaire, a standard screen for the retrospective assessment of ACEs. The questionnaire encompasses 10 items, one for each ACE. The single items are: emotional, physical and sexual abuse, emotional and physical neglect, separation of parents, mental illness, substance abuse and incarceration of a household member and violence against the mother in a dichotomous manner (yes/no). Psychometric properties of the German version of the ACE were demonstrated by Wingenfeld and colleagues with a satisfying internal consistency (Cronbachs $\alpha=076$ ) [28]. In our sample, Cronbachs $\alpha$ was 0.77 . Life satisfaction was assessed via a self-rating by the question" How satisfied are you, all in all, with your life?", scale 1 (not satisfied at all) to 11 (totally satisfied) after Beierlein and colleagues [29]. General health status was assessed with the EuroQol visual analogue scale (EQ VAS) with the question" How good or bad you think your personal health is today?", scale 0 (worst) to 100 (best) [30]. Depressive symptoms were assessed with the Patient Health Questionnaire-2 (PHQ-2), a screening tool with a sensitivity of $82 \%$ and a specificity of $92 \%$ for major depressive disorder for a cut-point of $\geq 3$ [31]. Anxiety was assessed with the Generalized Anxiety Disorder 2-item (GAD-2), a screening questionnaire with a sensitivity of $86 \%$ and a specificity of $83 \%$ for generalized anxiety disorder for a cut-point of $\geq 3$ [32]. In our sample, Cronbachs $\alpha$ was 0.78 for the PHQ-2 and 0.80 for the GAD-2.

\subsection{Participants}

Of the $\mathrm{N}=2531$ participants, between 2,501-2,526 participants (depending on the analysis) were included in the sample. The others were excluded due to missings on the respective data. Participants were on average 48.6 years old $(S D=18.0)$ and $56.4 \%$ were female. $96 \%$ reported to have German citizenship. The sample was representative for the German population in regard to age and gender compared to. The characteristics of the sample are presented in Table 1.

\subsection{Statistical analyses}

All analyses were conducted using SPSS version 21. Descriptive analyses were performed for prevalence rates. Comparisons were performed by $\mathrm{Chi}^{2}$ - or t-tests depending on measurement level. Risks were calculated by Odds Ratios using $\mathrm{Chi}^{2}$-tests.

Mediation analyses were performed with the macro PROCESS by Hayes [33] for SPSS. Ordinary last squares path analyses were conducted using 5000 bootstrapping samples. The presence or absence of household mental illness, substance abuse, violence against the mother, incarceration of a household member and parental separation were used in separate simple linear regression analysis as independent variable. Depending on the analyses, depression via PHQ score, anxiety as GAD score, life satisfaction and self-reported health were used as dependent variables. The number of experienced different maltreatment subtypes (0-5; emotional abuse, physical abuse, sexual abuse, emotional neglect, physical neglect) served as mediation variable. The direct association is presented as c, the indirect association as c'.

\section{Results}

In total, participants reported they had experienced a mean number of $1.03( \pm 1.70)$ of ACEs during childhood. In detail, a total
Table 1

Sample Characteristics.

\begin{tabular}{|c|c|}
\hline & Total $(n=2531)$ \\
\hline Age (M, SD) & $48.6(18.0)$ \\
\hline \multicolumn{2}{|l|}{ Gender (n, \%) } \\
\hline Female & $1401(55.4)$ \\
\hline Male & $1130(44.6)$ \\
\hline Living with a partner (n, \%) & $1351(53.4)$ \\
\hline Subjects with own Children (n, \%) & $1586(62.7)$ \\
\hline German Citizenship (n, \%) & $2429(96.0)$ \\
\hline \multicolumn{2}{|l|}{ Educational level (n, \%) } \\
\hline Left school before graduation & $56(2.2)$ \\
\hline School graduation & $2,169(85.7)$ \\
\hline Academic degree & $233(9.2)$ \\
\hline Attending school & $65(2.6)$ \\
\hline \multicolumn{2}{|l|}{ Household Dysfunction (n, \%) } \\
\hline Violence against the mother & $248(9.8)$ \\
\hline Household substance abuse & $421(16.6)$ \\
\hline Household mental illness & $267(10.5)$ \\
\hline Parental separation & $488(19.3)$ \\
\hline Household incarceration & $88(3.5)$ \\
\hline \multicolumn{2}{|l|}{ Child Maltreatment (n, \%) } \\
\hline Emotional Abuse & $316(12.5)$ \\
\hline Physical Abuse & $230(9.1)$ \\
\hline Sexual Abuse & $109(4.3)$ \\
\hline Emotional Neglect & $338(13.4)$ \\
\hline Physical Neglect & $109(4.3)$ \\
\hline Number of experienced ACEs (M, SD) & $1.03(1.70)$ \\
\hline Significant depressive symptoms (PHQ-2 $\geq 3$ ) & $253(10.0)$ \\
\hline Significant anxiety (PHQ-2 $\geq 3$ ) & $287(11.3)$ \\
\hline Life satisfaction & $8.02(2.52)$ \\
\hline Subjective general health & $78.92(20.21)$ \\
\hline
\end{tabular}

Sample Characteristics. Data are presented as mean (M) and standard deviation (SD) for age, life satisfaction and subjective general health and number of subjects (\%) for other characteristics.

of $n=248$ (9.8\%) reported they had witnessed violence against the mother, $421(16.6 \%)$ had lived with a household member with substance abuse and 267 (10.5\%) had lived with a household member with mental illness in childhood. 488 (19.3\%) reported that they had experienced parental separation and 88 (3.5\%) had an incarcerated household member. Regarding child maltreatment, 316 (12.5\%) of the participants reported emotional abuse, 230 (9.1\%) physical abuse, 109 (4.3\%) sexual abuse, 338 (13.4\%) emotional neglect and 109 (4.3\%) physical neglect (see Table 1).

\subsection{Household dysfunction is associated with increased risk for all subtypes of child maltreatment}

Prevalence of all subtypes of child maltreatment increased, when any one of the assessed household dysfunctions - mental illness, substance abuse, violence against the mother, incarceration of a household member or parental separation - was reported.

In detail, household mental illness was associated with an increased risk for all child maltreatment subtypes (ORs 4.95-5.55), household substance abuse with increased risks between five- and sevenfold (ORs 5.32-6.98) and violence against the mother with increased risks between four- and tenfold (ORs 4.43-10.26). The strongest increase for the risk of child maltreatment was seen if incarceration of a household member was reported (ORs 6.1114.93, depending of the maltreatment subtype), the lowest increase if parental separation had occurred (ORs 3.37-4.87; for details see Table 2). 
Table 2

Prevalence and risk of child maltreatment in dependence of household mental illness, substance abuse and violence against the mother.

\begin{tabular}{|c|c|c|c|c|c|c|c|c|c|c|}
\hline & \multicolumn{2}{|c|}{$\begin{array}{l}\text { Violence against the } \\
\text { mother }\end{array}$} & \multicolumn{2}{|c|}{$\begin{array}{l}\text { Substance misuse } \\
\text { within household }\end{array}$} & \multicolumn{2}{|c|}{$\begin{array}{l}\text { Household mental } \\
\text { illness }\end{array}$} & \multicolumn{2}{|c|}{ Parental separation } & \multicolumn{2}{|c|}{$\begin{array}{l}\text { Incarceration of a } \\
\text { household member }\end{array}$} \\
\hline & $\begin{array}{l}\text { Yes } \\
(n=247- \\
248)\end{array}$ & $\begin{array}{l}\text { No } \\
(n=2,259- \\
2,263)\end{array}$ & $\begin{array}{l}\text { Yes } \\
(n=418- \\
420)\end{array}$ & $\begin{array}{l}\text { No } \\
(\mathrm{n}=2,235- \\
2,239)\end{array}$ & $\begin{array}{l}\text { Yes } \\
(n=264- \\
266)\end{array}$ & $\begin{array}{l}\text { No } \\
(n=2,237- \\
2,239)\end{array}$ & $\begin{array}{l}\text { Yes } \\
(n=480- \\
486)\end{array}$ & $\begin{array}{l}\text { No } \\
(n=2,008- \\
2,026)\end{array}$ & $\begin{array}{l}\text { Yes } \\
(n=87- \\
88)\end{array}$ & $\begin{array}{l}\text { No } \\
(n=2,400- \\
2,423)\end{array}$ \\
\hline Emotional Abuse (n, \%) & $100(40.5)$ & $215(9.5)$ & $\begin{array}{l}146 \\
(34.8)\end{array}$ & $169(8.1)$ & $99(37.2)$ & $216(9.6)$ & $\begin{array}{l}125 \\
(25.7)\end{array}$ & $189(9.3)$ & $48(54.5)$ & $265(10.9)$ \\
\hline OR for Emotional Abuse (95 CI) & $\begin{array}{l}6.48(4.85- \\
8.66)\end{array}$ & & $\begin{array}{l}6.11 \\
(4.73- \\
7.88)\end{array}$ & & $\begin{array}{l}5.55 \\
(4.17- \\
7.39)\end{array}$ & & $\begin{array}{l}3.37 \\
(2.61- \\
4.33)\end{array}$ & & $\begin{array}{l}6.11(4.73- \\
7.88)\end{array}$ & \\
\hline $\mathrm{Chi}^{2}$ & $194.81^{* * *}$ & & $229.09^{* * *}$ & & $164.40^{* * *}$ & & $96.29^{* * * *}$ & & $148.00^{* * * *}$ & \\
\hline Physical Abuse (n, \%) & $90(36.4)$ & $138(6.1)$ & $117(27.9)$ & $112(5.3)$ & $72(27.1)$ & $156(7.0)$ & $94(19.3)$ & $133(6.6)$ & $48(54.5)$ & $180(7.4)$ \\
\hline OR for Physical Abuse (95 CI) & $\begin{array}{l}8.81(6.46- \\
12.03)\end{array}$ & & $\begin{array}{l}6.86 \\
(5.15- \\
9.13)\end{array}$ & & $\begin{array}{l}4.95 \\
(3.61- \\
6.78)\end{array}$ & & $\begin{array}{l}3.41 \\
(2.56- \\
4.53)\end{array}$ & & $\begin{array}{l}14.93 \\
(9.55- \\
23.32)\end{array}$ & \\
\hline $\mathrm{Chi}^{2}$ & $247.63^{* * *}$ & & $214.98^{* * *}$ & & $115.77^{* * *}$ & & $77.55^{* * *}$ & & $227.89^{* * *}$ & \\
\hline Sexual Abuse $(n, \%)$ & $33(13.4)$ & $76(3.4)$ & $54(12.9)$ & $55(2.6)$ & $39(14.7)$ & $69(3.1)$ & $47(9.7)$ & $62(3.1)$ & $20(22.7)$ & $89(3.7)$ \\
\hline OR for Sexual Abuse (95 CI) & $\begin{array}{l}4.43(2.88- \\
6.83)\end{array}$ & & $\begin{array}{l}5.47 \\
(3.70- \\
8.10)\end{array}$ & & $\begin{array}{l}5.40 \\
(3.56- \\
8.18)\end{array}$ & & $\begin{array}{l}3.39 \\
(2.29- \\
5.02)\end{array}$ & & $\begin{array}{l}7.70(4.48- \\
13.24)\end{array}$ & \\
\hline $\mathrm{Chi}^{2}$ & $53.55^{* * *}$ & & $88.34^{* * * *}$ & & $77.18^{* * *}$ & & $41.15^{* * *}$ & & $74.12^{* * *}$ & \\
\hline Emotional Neglect (n, \%) & $95(38.3)$ & $243(10.8)$ & $\begin{array}{l}146 \\
(34.9)\end{array}$ & $192(9.2)$ & $99(37.5)$ & $239(10.7)$ & $137(28.4)$ & $201(9.9)$ & $40(46.0)$ & $296(12.2)$ \\
\hline OR for Emotional Neglect (95 CI) & $\begin{array}{l}5.15(3.86- \\
6.88)\end{array}$ & & $\begin{array}{l}5.32 \\
(4.15- \\
6.83)\end{array}$ & & $\begin{array}{l}5.02 \\
(3.78- \\
6.66)\end{array}$ & & $\begin{array}{l}3.61 \\
(2.82- \\
4.61)\end{array}$ & & $\begin{array}{l}6.11(3.94- \\
9.47)\end{array}$ & \\
\hline $\mathrm{Chi}^{2}$ & $145.51^{* * *}$ & & $198.85^{* * *}$ & & $145.49^{* * *}$ & & $114.31^{* * *}$ & & $82.40^{* * *}$ & \\
\hline Physical Neglect (n, \%) & $52(21.0)$ & $57(2.5)$ & $60(14.3)$ & $49(2.3)$ & $38(14.3)$ & $70(3.1)$ & $56(11.6)$ & $53(2.6)$ & $27(31.0)$ & $82(3.4)$ \\
\hline OR for Physical Neglect (95 CI) & $\begin{array}{l}10.26 \\
(6.85- \\
15.35)\end{array}$ & & $\begin{array}{l}6.98 \\
(4.71- \\
10.35)\end{array}$ & & $\begin{array}{l}5.19 \\
(3.41- \\
7.87)\end{array}$ & & $\begin{array}{l}4.87 \\
(3.30- \\
7.19)\end{array}$ & & $\begin{array}{l}12.84 \\
(7.75- \\
21.64)\end{array}$ & \\
\hline $\mathrm{Chi}^{2}$ & $183.00^{* * *}$ & & $120.92^{* * *}$ & & $72.14^{* * *}$ & & $75.35^{* * *}$ & & $154.41^{* * *}$ & \\
\hline $\begin{array}{l}\text { Number of experienced child } \\
\text { maltreatment subtypes (M, SD) }\end{array}$ & $1.50(1.64)$ & $0.32(0.81)$ & $\begin{array}{l}1.25 \\
(1.51)\end{array}$ & $0.26(0.75)$ & $\begin{array}{l}1.32 \\
(1.50)\end{array}$ & $0.34(0.86)$ & $\begin{array}{l}0.95 \\
(1.41)\end{array}$ & $0.32(0.82)$ & $2.10(1.71)$ & $0.38(0.90)$ \\
\hline $\mathrm{F}$ & $464.27^{* * * *}$ & & $605.67^{* * * *}$ & & $290.71^{* * *}$ & & $318.65^{* * *}$ & & $154.20^{* * *}$ & \\
\hline
\end{tabular}

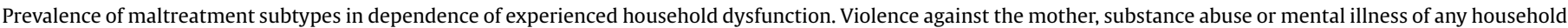
member. Presented as Number (N) and Percentages (\%) or odds ratios (OR) and 95\% Confidence Interval (CI).

$\mathrm{p}<0.001$.

The mean number of experienced maltreatment subtypes increased in case of any reported ACE linked to household dysfunction (for details see Table 2).

\subsection{Child maltreatment mediates the long-term consequences of household dysfunction}

The association of violence against the mother with depression, anxiety and general health status was mediated completely by child maltreatment. The association of IPV and these outcomes approached zero and lost statistical significance if child maltreatment was included in the calculation. The association with life satisfaction was partially mediated via child maltreatment. The association was reduced by half after inclusion of child maltreatment and still statistically significant (for details see Fig. 2).

Child maltreatment partially mediated also the association of household substance abuse with all assessed long-term outcomes (for details see Fig. 3).

The association of mental illness of a household member with depression, anxiety, life satisfaction and general health was mediated partially by child maltreatment (for details see Fig. 4).

The association of an incarcerated household member with depression, anxiety and general health status was mediated completely by child maltreatment, meaning that these associations can be explained with the higher risks for maltreatment in the case of incarceration of a household member. The association of an incarcerated household member with life satisfaction was partially mediated via child maltreatment (for details see Fig. 5).

The association of parental separation with depression and anxiety was mediated partially by child maltreatment. The association was reduced by more than half after inclusion of child maltreatment. The association of parental separation with life satisfaction was mediated completely by child maltreatment. There was no significant association seen for parental separation and subjective general health status (for details see Fig. 6).

\section{Discussion}

This is the first study to investigate the association of ACEs linked to household dysfunction and child maltreatment in a representative sample in Europe. The present analysis shows strongly increased risks for physical, emotional and sexual abuse as well as physical and emotional neglect during childhood if violence against the mother, substance abuse or mental illness of any household member during childhood was reported. Strikingly, our results demonstrate that the assessed long-term consequences of household dysfunction regarding the health of affected children are mediated partly or completely by child maltreatment. The enhanced risk for child maltreatment of household dysfunction is known. Felitti et al. showed a high correlation between different 
A

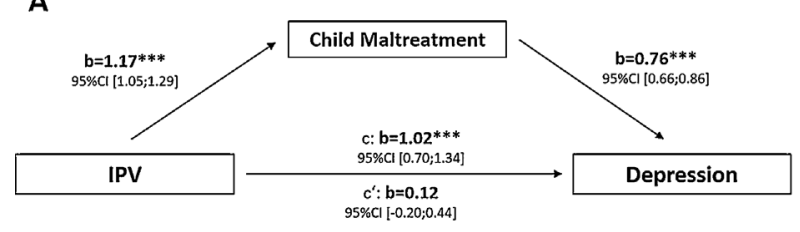

C

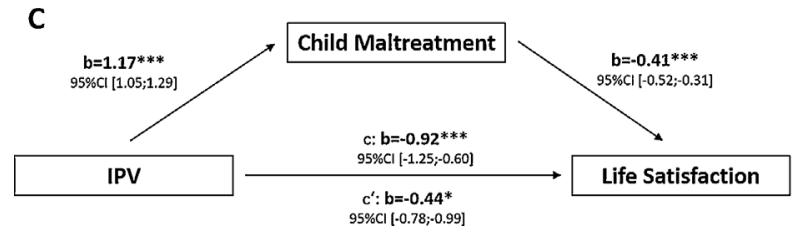

B

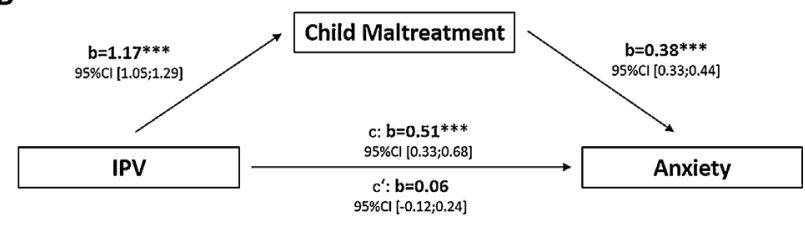

D

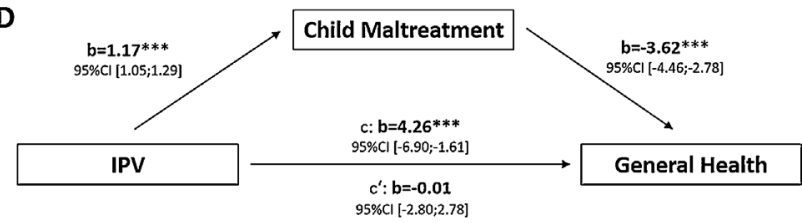

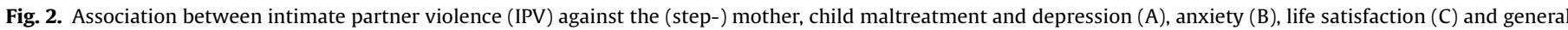

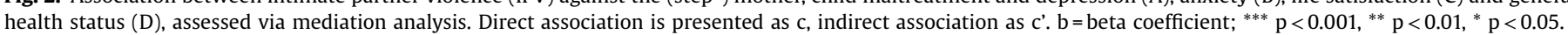

A

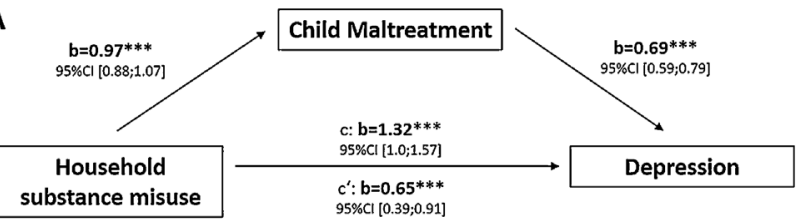

C

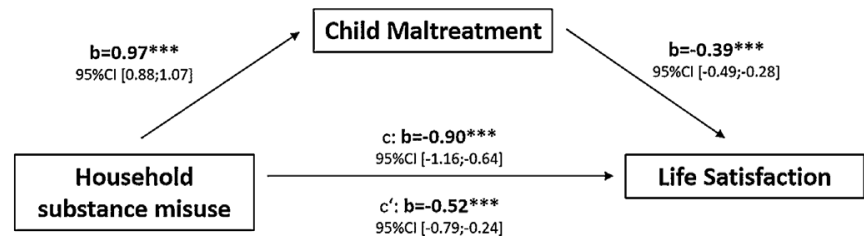

B

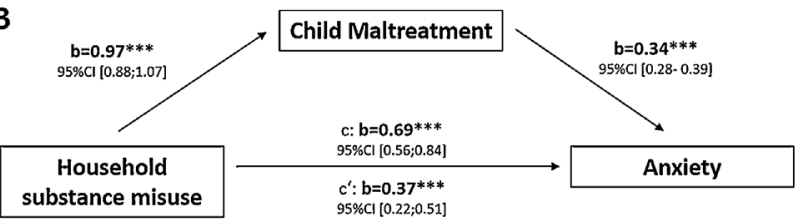

D

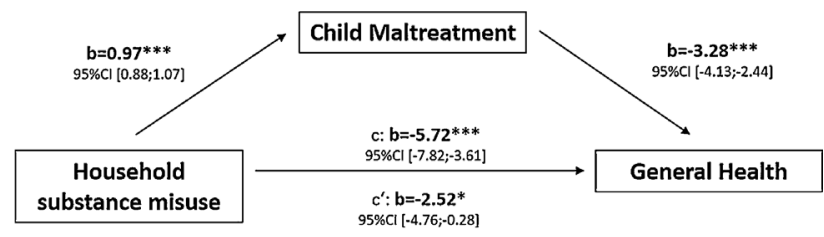

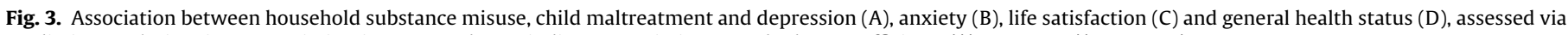
mediation analysis. Direct association is presented as c, indirect association as $\mathrm{c}^{\prime}$. $\mathrm{b}=$ beta coefficient; ${ }^{* * *} \mathrm{p}<0.001,{ }^{* *} \mathrm{p}<0.01,{ }^{*} \mathrm{p}<0.05$.

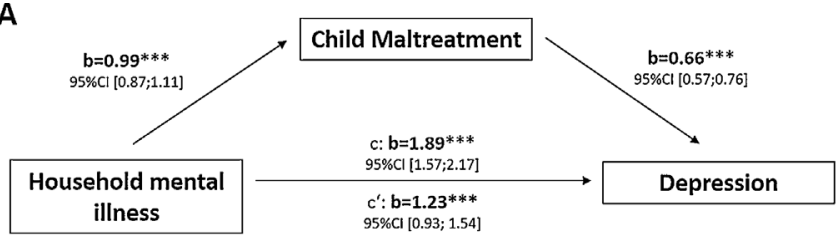

C

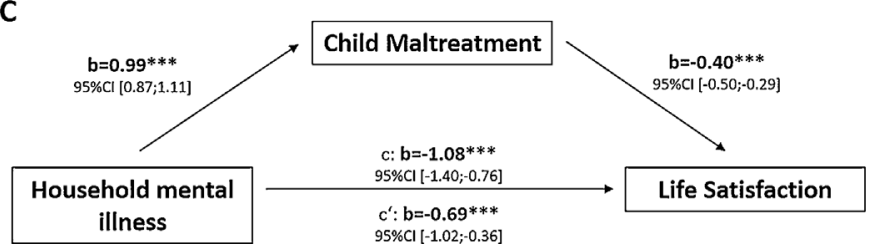

B

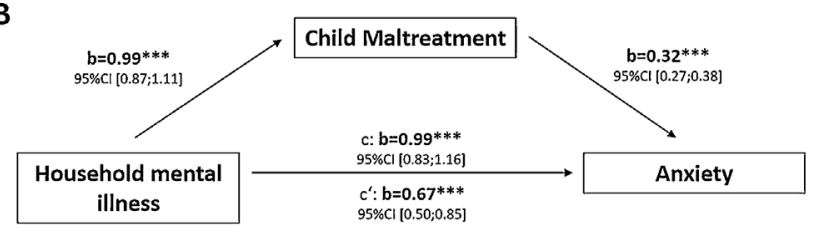

D

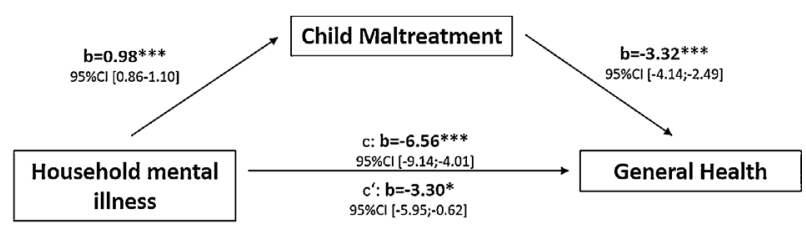

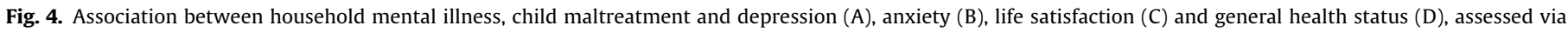
mediation analysis. Direct association is presented as c, indirect association as c'. $\mathrm{b}=$ beta coefficient; ${ }^{* * *} \mathrm{p}<0.001,{ }^{* *} \mathrm{p}<0.01,{ }^{*} \mathrm{p}<0.05$.

adverse childhood events in the original ACE Study [24]. In a later analyses based on the same data, Felitti et al. showed increased ratios for child maltreatment in case of household substance abuse (odds ranging between 2.1-3.0 in dependence of the subtype of maltreatment), mental illness (odds 2.1-4.2), domestic violence (odds 2.5-5.9), incarcerated household member (odds 2.3-2.7) and parental separation (odds 2.0-2.6) [34]. A study from Ohashi and colleagues showed in a Japanese sample that the risk for child maltreatment increases with the number of ACEs related to household dysfunction [35]. In an Australian study, where a sample of 7223 mothers and their offspring was assessed, odds for maltreatment ranged between 2.0 and 3.5 in case of IPV in 

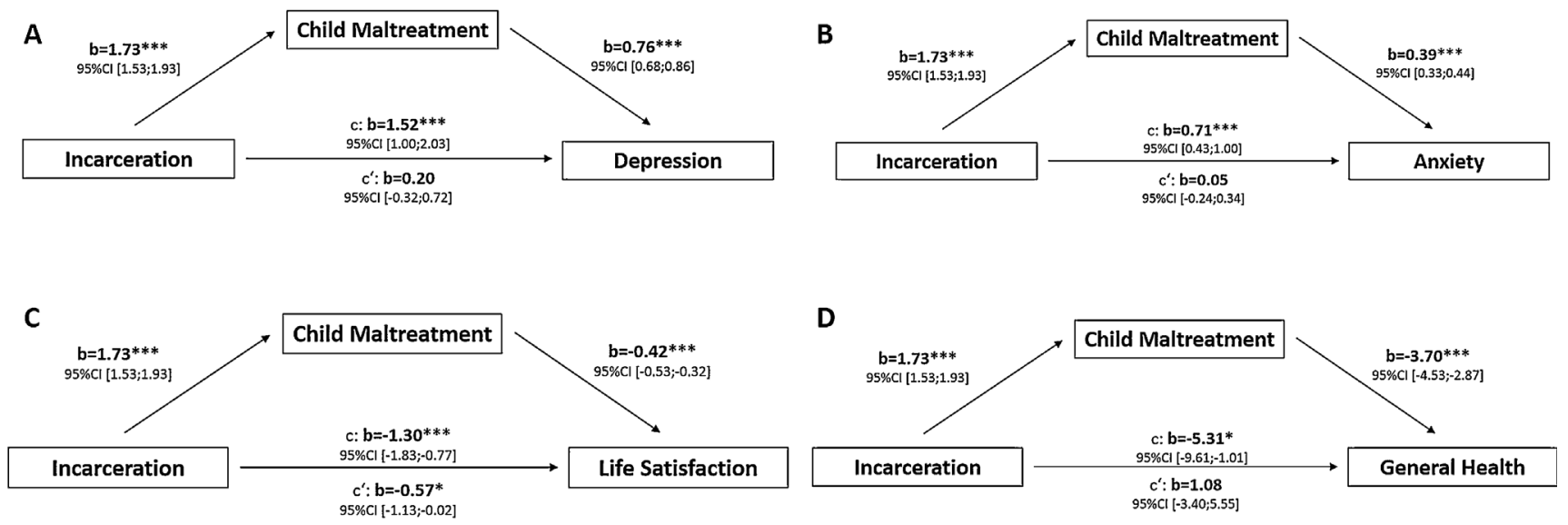

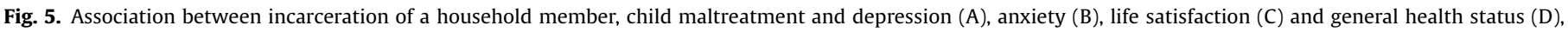

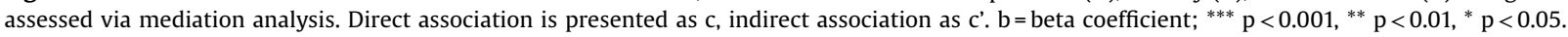
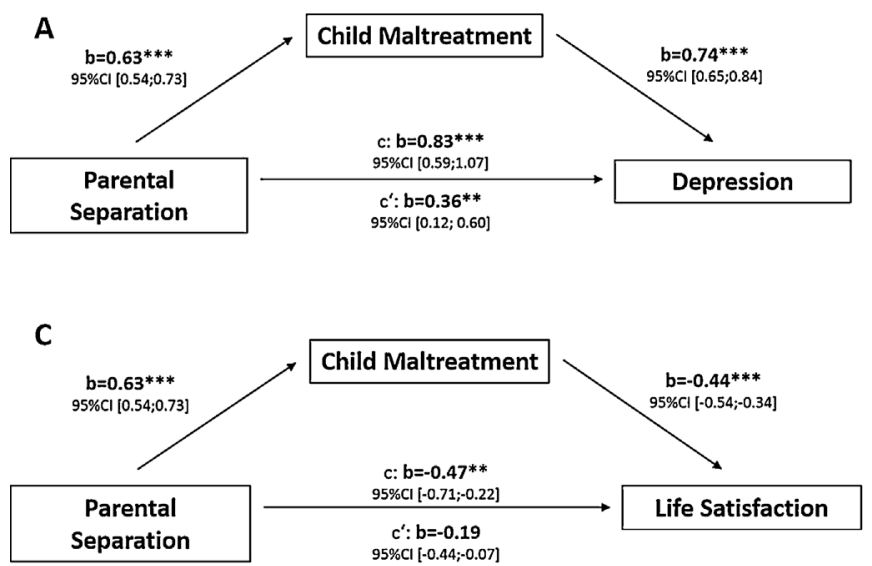

D
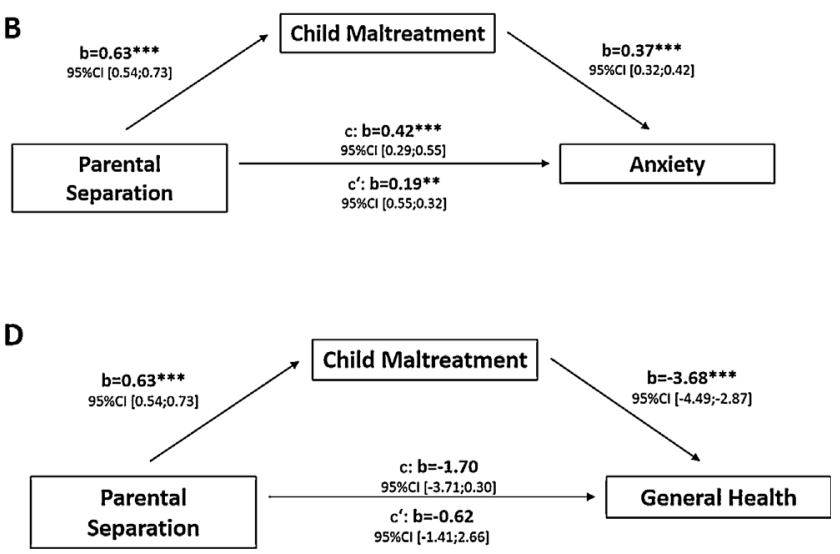

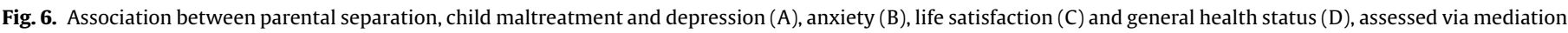
analysis. Direct association is presented as $\mathrm{c}$, indirect association as $\mathrm{c}^{\prime}$. $\mathrm{b}=$ beta coefficient; ${ }^{* * *} \mathrm{p}<0.001,{ }^{* *} \mathrm{p}<0.01,{ }^{*} \mathrm{p}<0.05$.

dependence of maltreatment subtype and gender of the child [27]. As all these data, including the here presented results, are based on retrospective self-report that may be affected by recall bias. This could result in an underestimation of the presented results and it should be kept in mind that odds for maltreatment may be even higher.

Reasons for the increased risk of maltreatment in dysfunctional households might be multifactorial. Socioeconomic status, isolation, stigma are risk factors for but also a result of ACEs [24,36-42]. It is this interwoven relationship of risk factors that makes it so complex to identify the crucial starting points for preventive measures. Other, more specific factors linked to household dysfunction encompass e.g. the parental ability to control impulses and to cope with frustration and anger - skills and capacity needed to manage daily requirements and stress as well as to maintain a warm and secure relationship to a child [43-46]. Parental separation and incarceration of a household member can be linked to impairment of the relationship or even loss of contact to primary caregiver $[17,18]$.

In the present analyses, we found the highest risks for maltreatment for incarceration of a household member and violence against the mother. Furthermore, in contrast to household substance abuse and mental disorders, the associations of incarceration and IPV with anxiety, depression and general health status were mediated completely by child maltreatment. This suggests that long-term consequences for the health of affected children and adolescents may be prevented if interventions focus on child protection and maltreatment could be hindered. This suggests that prevention of long term consequences for affected children always need to focus these children directly. There might be no such thing as "collateral benefit" to the children when household dysfunction is improved without assessment of child maltreatment. A close link between IPV and all forms of child maltreatment is known from the literature [47]. A parent who uses physical violence against the partner is at higher risk to be violent against other parts of the family. Perpetrators of IPV are often low in dispositional self-control, have lower self-regulatory resources and higher aggressive potential [48]. Therefore, the increased risks we could show for not only physical abuse, but also other maltreatment subtypes, are not surprising. Moreover, IPV is usually going along with witnessing of domestic violence and exposure to verbal aggression for the child [26]. In an observational study including a sample of 554 subjects, Teicher and colleagues emphasized the role of IPV by showing that the effect of domestic violence and verbal abuse combined was higher than the effect of familiar sexual abuse on long-term outcomes including depression and anxiety [49]. Incarceration is often going along with a sudden loss of a household member and increased stress, a loss of financial and social support, and a higher workload for the remaining family [50]. Furthermore, incarceration might be due to aggressive 
behavior that may have also been directed against family members including children.

The associations of the assessed long-term consequences of household substance misuse, mental illness and parental separation were mediated partly by child maltreatment, suggesting that significant parts of the long-term consequences of affected children could be prevented by effective protection from maltreatment.

Taken together, our results demonstrate that children living in dysfunctional households are at higher risk for maltreatment and therefore should be considered by tailored preventive strategies. There are known obstacles to target these high-risk families. Reasons include fear of stigmatization and loss of custody at the family side [51,52] and a lack of systematical screening for underage children in families where household dysfunctions become evident, e.g. in adult psychiatric care, on the institutional side. Nevertheless, there are some promising results that interventions targeting these high-risk families can be successful. One randomized controlled trial (RCT) showed that an intervention including social support, psycho-education and coping skills training can help to reduce the consequences of ACEs linked to household dysfunction [53]. Furthermore, a meta-analysis focusing on children with mentally ill parents showed that after interventions including cognitive, behavioral, or psychoeducational components, the risk for the children to develop a mental disorder can be decreased by $40 \%$ [54]. Levey et colleagues demonstrated in a meta-analyses that the risk for child maltreatment in high-risk families, including maternal mental illness and substance abuse and IPV, can be decreased significantly by regular home-visiting, whereas there is a lack of evidence for other interventions [55]. These studies point out that interventions targeting ACEs linked to household dysfunctions can be effective.

Nevertheless, to design specific, targeted programs, there is a need to identify the pivotal mechanisms leading to the deleterious consequences of household dysfunction. The present analyses reveals a significant mediation of child maltreatment for the association between all assessed forms of household dysfunction and mental health, life satisfaction and self-rated health condition. These results underline the pivotal role of child maltreatment on various outcomes later in life and implies that effective interventions for families with household dysfunction need to ensure child protection as a priority. As age under 4 years is not only a known risk factor for maltreatment [56] - but also an age period that is particularly vulnerable $[57,58]$ - interventions should start as soon as possible, e.g. during pregnancies.

However, only the long-term consequences to mental and general health of IPV and incarceration of a household member were mediated completely by maltreatment. The other consequences were mediated only partly. Therefore, other factors seem to be relevant as well. Next to maltreatment, the interaction of parents to the child are known to impact the development of children enormously [8]. The experience of IPV was shown to affect the attachment style of mothers massively [14], which again is known to affect children [59]. In mothers with depression, the attachment style was shown to mediate the association between mothers psychopathology and child's emotional responsiveness [15]. Furthermore, parenting skills and parent-child interactions, that are known to be impaired in mothers who have experienced IPV [14], in mentally ill [15] and substance abusing parents [16], are discussed, just as biological and socioeconomic factors $[19,20]$.

\subsection{Limitations}

Nevertheless, there are some limitations to consider. The here shown results for ACEs are based on a retrospective self-report. In all retrospective analyses, there is a potential for underreporting due to recall bias. This can be the result of denial, embarrassment and misunderstanding $[60,61]$ and to a potential underestimation of the here shown results. Another limitation is that the age of the subject at the time of maltreatment was not assessed. Teicher and colleagues were able to show that not only the type, but furthermore the timing of maltreatment in different development stages is relevant for the long-term consequences of maltreatment $[62,63]$. Moreover, as this is an observational study with a crosssectional approach, causality cannot be deduced. However, the presented results give a meaningful insight into the relevance of child maltreatment for the comprehensive consequences of household dysfunction.

\section{Conclusion}

The present analysis demonstrates that the occurrence of substance abuse and mental illness of any household member, violence against the mother, incarceration of a household member and parental separation during childhood is associated with an increased risk for all subtypes of child maltreatment and moreover, that the assessed deleterious consequences of household dysfunction are mediated by child maltreatment. These results underline the role of prevention of child maltreatment in families with household dysfunction and implies child protection as an integral part of any intervention. As children under the age of 4 years are not only particularly vulnerable for maltreatment, but also for its consequences, early screenings of families with known household dysfunctions are recommendable. This requires comprehensive cooperation between different agencies, such as child protection services, law enforcement, healthcare and welfare.

\section{Funding}

Not applicable.

\section{Compliance with ethical standards}

All procedures performed were in accordance with the ethical standards of the institutional research committee of the University Leipzig and with the Declaration of Helsinki. Written informed consent was obtained from all individual participants included in the study.

\section{Conflict of interest}

VC, OB, AW, CS, EB and BS state that they have no conflict interests.

JMF has received research funding from the EU, DFG (German Research Foundation), BMG (Federal Ministry of Health), BMBF (Federal Ministry of Education and Research), BMFSFJ (Federal Ministry of Family, Senior Citizens, Women and Youth), German armed forces, several state ministries of social affairs, State Foundation Baden-Württemberg, Volkswagen Foundation, European Academy, Pontifical Gregorian University, RAZ, CJD, Caritas, Diocese of Rottenburg-Stuttgart. Moreover, he received travel grants, honoraria and sponsoring for conferences and medical educational purposes from DFG, AACAP, NIMH/NIH, EU, Pro Helvetia, Janssen-Cilag (J\&J), Shire, several universities, professional associations, political foundations, and German federal and state ministries during the last 5 years. Every grant and every honorarium has to be declared to the law office of the University Hospital Ulm. Professor Fegert holds no stocks of pharmaceutical companies.

PLP has received research funding from the Bundesinstitut für Arzneimittel und Medizinprodukte, BMBF (Federal Ministry of Education and Research), VW-Foundation, Baden-Württemberg 
Stiftung, Lundbeck, Servier. Professor Plener holds no stocks of pharmaceutical companies.

\section{References}

[1] Hughes K, Bellis MA, Hardcastle KA, Sethi D, Butchart A, Mikton C, et al. The effect of multiple adverse childhood experiences on health: a systematic review and meta-analysis. Lancet Public Health 2017;2(8):e356-66.

[2] Dong M, Anda RF, Felitti VJ, Dube SR, Williamson DF, Thompson TJ, et al. The interrelatedness of multiple forms of childhood abuse, neglect, and household dysfunction. Child Abuse Negl 2004;28(7):771-84.

[3] Brown SM, Rienks S, McCrae JS, Watamura SE. The co-occurrence of adverse childhood experiences among children investigated for child maltreatment: latent class analysis. Child Abuse Negl 2017;87:18-27.

[4] Brown DW, Anda RF, Tiemeier H, Felitti VJ, Edwards VJ, Croft JB, et al. Adverse childhood experiences and the risk of premature mortality. Am J Prev Med 2009;37(5):389-96.

[5] Norman RE, Byambaa M, De R, Butchart A, Scott J, Vos T. The long-term health consequences of child physical abuse, emotional abuse, and neglect: a systematic review and meta-analysis. PLoS Med 2012;9(11)e1001349.

[6] Habetha S, Bleich S, Weidenhammer J, Fegert JM. A prevalence-based approach to societal costs occurring in consequence of child abuse and neglect. Child Adolesc Psychiatry Ment Health 2012;6(1):35.

[7] Neamah HH, Sudfeld C, McCoy DC, Fink G, Fawzi WW, Masanja H, et al Intimate partner violence, depression, and child growth and development. Pediatrics 2018;142(1).

[8] World Health Organization. The importance of caregiver-child interactions for the survival and healthy development of young children: a review. 2004. http:// www.who.int/maternal_child_adolescent/documents/924159134X/en/.

[9] Slopen N, McLaughlin K. Exposure to intimate partner violence and parental depression increases risk of ADHD in preschool children. Evid Based Ment Health 2013;16(4):102.

[10] Menon SV, Cohen JR, Shorey RC, Temple JR. The impact of intimate partner violence exposure in adolescence and emerging adulthood: a developmental psychopathology approach. J Clin Child Adolesc Psychol 2018;1-12.

[11] Brockington I, Chandra P, Dubowitz H, Jones D, Moussa S, Nakku J, et al. WPA guidance on the protection and promotion of mental health in children of persons with severe mental disorders. World Psychiatry 2011:10(2):93-102.

[12] Rasic D, Hajek T, Alda M, Uher R. Risk of mental illness in offspring of parents with schizophrenia, bipolar disorder, and major depressive disorder: a metaanalysis of family high-risk studies. Schizophr Bull 2014;40(1):28-38.

[13] Bowen E. The impact of intimate partner violence on preschool children's peer problems: an analysis of risk and protective factors. Child Abuse Negl 2015;50:141-50.

[14] Levendosky A, Bogat GA, Huth-Bocks A. The influence of domestic violence on the development of the attachment relationship between mother and young child. Psychoanal Psychol 2011;28(4):512-27.

[15] Widom CS, Czaja SJ, Kozakowski SS, Chauhan P. Does adult attachment style mediate the relationship between childhood maltreatment and mental and physical health outcomes? Child Abuse Negl 2018;76:533-45.

[16] Kelley ML, Lawrence HR, Milletich RJ, Hollis BF, Henson JM. Modeling risk for child abuse and harsh parenting in families with depressed and substanceabusing parents. Child Abuse Negl 2015;43:42-52.

[17] Woodward L, Fergusson DM, Belsky J. Timing of parental separation and attachment to parents in adolescence: results of a prospective study from birth to age 16. J Marriage Fam 2000;62(1):162-74.

[18] Dallaire DH. Children with incarcerated mothers: developmental outcomes, special challenges and recommendations. J Appl Dev Psychol 2007;28(1):1524.

[19] Goodman SH. Depression in mothers. Annu Rev Clin Psychol 2007;3:107-35.

[20] van Santvoort F, Hosman CMH, Janssens JMAM, van Doesum KTM, Reupert A van Loon LMA. The impact of various parental mental disorders on children's diagnoses: a systematic review. Clin Child Fam Psychol Rev 2015;18(4):28199.

[21] Averdijk M, Malti T, Eisner M, Ribeaud D. Parental separation and child aggressive and internalizing behavior: an event history calendar analysis. Child Psychiatry Hum Dev 2012;43(2):184-200.

[22] Brown J, Cohen P, Johnson JG, Salzinger S. A longitudinal analysis of risk factors for child maltreatment: findings of a 17-year prospective study of officially recorded and self-reported child abuse and neglect. Child Abuse Negl 1998;22 (11):1065-78.

[23] Mulder TM, Kuiper KC, van der Put CE, Stams G-JJM, Assink M. Risk factors for child neglect: a meta-analytic review. Child Abuse Negl 2018;77:198-210.

[24] Felitti VJ, Anda RF, Nordenberg D, Williamson DF, Spitz AM, Edwards V, et al. Relationship of childhood abuse and household dysfunction to many of the leading causes of death in adults. The Adverse Childhood Experiences (ACE) Study. Am J Prev Med 1998;14(4):245-58.

[25] Gilbert R, Kemp A, Thoburn J, Sidebotham P, Radford L, Glaser D, et al. Recognising and responding to child maltreatment. Lancet 2009;373 (9658):167-80.

[26] MacMillan HL, Wathen CN, Varcoe CM. Intimate partner violence in the family: considerations for children's safety. Child Abuse Negl 2013;37 (12):1186-91.
[27] Ahmadabadi Z, Najman JM, Williams GM, Clavarino AM, d'Abbs P, Abajobir AA. Maternal intimate partner violence victimization and child maltreatment. Child Abuse Negl 2018;82:23-33.

[28] Wingenfeld K, Schäfer I, Terfehr K, Grabski H, Driessen M, Grabe H, et al Reliable, valide und ökonomische Erfassung früher Traumatisierung: Erste psychometrische Charakterisierung der deutschen Version des Adverse Childhood Experiences Questionnaire (ACE). Psychother Psych Med 2011;61 (01):e10-4.

[29] C. Beierlein, A. Kovaleva, Z. László, C.J. Kemper, B. Rammstedt, Kurzskala zur Erfassung der Allgemeinen Lebenszufriedenheit (L-1). Zusammenstellung sozialwissenschaftlicher Items und Skalen. https://www.gesis.org/ kurzskalen-psychologischer-merkmale/download/2015.

[30] Herdman M, Gudex C, Lloyd A, Janssen M, Kind P, Parkin D, et al. Development and preliminary testing of the new five-level version of EQ-5D (EQ-5D-5L). Qual Life Res 2011;20(10):1727-36.

[31] Lowe B, Kroenke K, Grafe K. Detecting and monitoring depression with a twoitem questionnaire (PHQ-2). J Psychosom Res 2005;58(2):163-71.

[32] Kroenke K, Spitzer RL, Williams JW, Monahan PO, Löwe B. Anxiety disorders in primary care: prevalence, impairment, comorbidity, and detection. Ann Intern Med 2007;146(5):317-25.

[33] Hayes AF. Introduction to mediation, moderation, and conditional process analysis a regression-based approach. New York: Guilford Publications, Inc.; 2013.

[34] Dong M, Anda RF, Felitti VJ, Dube SR, Williamson DF, Thompson TJ, et al. The interrelatedness of multiple forms of childhood abuse, neglect, and household dysfunction. Child Abuse Negl 2004;28(7):771-84.

[35] Ohashi H, Wada I, Yamaoka Y, Nakajima-Yamaguchi R, Ogai Y, Morita N. Cumulative risk effect of household dysfunction for child maltreatment after intensive intervention of the child protection system in Japan: a longitudinal analysis. Environ Health Prev Med 2018;23(1):14.

[36] Thornberry TP, Matsuda M, Greenman SJ, Augustyn MB, Henry KL, Smith CA, et al. Adolescent risk factors for child maltreatment. Child Abuse Negl 2014;38 (4):706-22.

[37] Capaldi DM, Knoble NB, Shortt JW, Kim HK. A systematic review of risk factors for intimate partner violence. Partner Abuse 2012;3(2):231-80.

[38] Brown J, Cohen P, Johnson JG, Salzinger S. A longitudinal analysis of risk factors for child maltreatment: findings of a 17-year prospective study of officially recorded and self-reported child abuse and neglect. Child Abuse Negl 1998;22 (11):1065-78.

[39] Whitesell M, Bachand A, Peel J, Familial Brown M. Social, and individual factors contributing to risk for adolescent substance use. J Addict 2013;2013:9.

[40] Pinto ACS, Luna IT, Sivla Ad A, Pinheiro PNd C, Braga VAB, ÂMAe Souza. Risk factors associated with mental health issues in adolescents: a integrative review. Revista da Escola de Enfermagem da USP 2014;48:555-64.

[41] Lee RD, Fang X, Luo F. The impact of parental incarceration on the physical and mental health of young adults. Pediatrics 2013;131(4):e1188-95.

[42] Ross J, Waterhouse-Bradley B, Contractor AA, Armour C. Typologies of adverse childhood experiences and their relationship to incarceration in U.S. Military veterans. Child Abuse Negl 2018;79:74-84.

[43] Bosanac P, Buist A, Burrows G. Motherhood and schizophrenic illnesses: a review of the literature. Aust N Z J Psychiatry 2003;37(1):24-30.

[44] Pels T, van Rooij FB, Distelbrink M. The impact of intimate partner violence (IPV) on parenting by mothers within an ethnically diverse population in the Netherlands. J Fam Violence 2015;30(8):1055-67.

[45] Niccols A, Milligan K, Sword W, Thabane L, Henderson J, Smith A. Integrated programs for mothers with substance abuse issues: a systematic review of studies reporting on parenting outcomes. Harm Reduct J 2012;9:14-.

[46] Parolin M, Simonelli A. Attachment theory and maternal drug addiction: the contribution to parenting interventions. Front Psychiatry 2016;7:152.

[47] Hamby S, Finkelhor D, Turner H, Ormrod R. The overlap of witnessing partner violence with child maltreatment and other victimizations in a nationally representative survey of youth. Child Abuse Negl 2010;34(10):734-41.

[48] Finkel EJ, DeWall CN, Slotter EB, Oaten M, Foshee VA. Self-regulatory failure and intimate partner violence perpetration. J Pers Soc Psychol 2009;97 (3):483-99.

[49] Teicher MH, Samson JA, Polcari A, McGreenery CE. Sticks, stones, and hurtful words: relative effects of various forms of childhood maltreatment. Am J Psychiatry 2006;163(6):993-1000.

[50] Nesmith A, Ruhland E. Children of incarcerated parents: challenges and resiliency, in their own words. Child Youth Serv Rev 2008:30(10):1119-30.

[51] Heard-Garris N, Winkelman TNA, Choi H, Miller AK, Kan K, Shlafer R, et al. Health care use and health behaviors among young adults with history of parental incarceration. Pediatrics 2018;142(3).

[52] Radcliffe P. Drug use and motherhood: strategies for managing identity. Drugs Alcohol Today 2009;9(3):17-21.

[53] van Santvoort F, Hosman CMH, van Doesum KTM, Janssens JMAM. Effectiveness of preventive support groups for children of mentally ill or addicted parents: a randomized controlled trial. Eur Child Adolesc Psychiatry 2014;23(6):473-84.

[54] Siegenthaler E, Munder T, Egger M. Effect of preventive interventions in mentally ill parents on the mental health of the offspring: systematic review and meta-analysis. J Am Acad Child Adolesc Psychiatry 2012;51(1)8-17 e8.

[55] Levey EJ, Gelaye B, Bain P, Rondon MB, Borba CPC, Henderson DC, et al. A systematic review of randomized controlled trials of interventions designed to decrease child abuse in high-risk families. Child Abuse Negl 2017;65:48-57. 
[56] Jackson AM, Kissoon N, Greene C. Aspects of abuse: recognizing and responding to child maltreatment. Curr Probl Pediatr Adolesc Health Care 2015;45(3):58-70.

[57] Green MJ, Tzoumakis S, McIntyre B, Kariuki M, Laurens KR, Dean K, et al. Childhood maltreatment and early developmental vulnerabilities at age 5 years. Child Dev 2018;89(5):1599-612.

[58] Cicchetti D. Socioemotional, personality, and biological development: illustrations from a multilevel developmental psychopathology perspective on child maltreatment. Annu Rev Psychol 2016;67(1):187-211.

[59] Murray L, Fiori-Cowley A, Hooper R, Cooper P. The impact of postnatal depression and associated adversity on early mother-infant interactions and later infant outcome. Child Dev 1996;67(5):2512-26.
[60] Gilbert R, Widom CS, Browne K, Fergusson D, Webb E, Janson S. Burden and consequences of child maltreatment in high-income countries. Lancet 2009;373(9657):68-81.

[61] Fergusson DM, Horwood LJ, Woodward LJ. The stability of child abuse reports: a longitudinal study of the reporting behaviour of young adults. Psychol Med 2000;30(3):529-44.

[62] SchalinskiI,TeicherMH,NischkD,HindererE,MüllerO, Rockstroh B.Type and timing of adverse childhood experiences differentially affect severity of PTSD, dissociative and depressive symptoms in adult inpatients. BMC Psychiatry 2016;16:295.

[63] Teicher MH, Anderson CM, Ohashi K, Khan A, McGreenery CE, Bolger EA, et al Differential effects of childhood neglect and abuse during sensitive exposure periods on male and female hippocampus. NeuroImage 2018;169:443-52. 